\title{
Endovascular and Surgical Treatment of Unruptured MCA Aneurysms: Meta-Analysis and Review of the Literature
}

\author{
Spiros L. Blackburn, ${ }^{1}$ Abdelrahman M. Abdelazim, ${ }^{1,2}$ Andrew B. Cutler, ${ }^{3}$ \\ Kevin T. Brookins, ${ }^{3}$ Kyle M. Fargen, ${ }^{1}$ Brian L. Hoh, ${ }^{1}$ and Yasha Kadkhodayan ${ }^{4}$ \\ ${ }^{1}$ University of Florida, Department of Neurosurgery, P.O. Box 100265, Gainesville, FL 32610-0265, USA \\ ${ }^{2}$ Assiut University, Department of Radiology, Assiut 71515, Egypt \\ ${ }^{3}$ University of Florida, College of Medicine, Gainesville, FL 32603, USA \\ ${ }^{4}$ Division of Interventional Neuroradiology, Abbott Northwestern Hospital, Minneapolis, MN 55407, USA
}

Correspondence should be addressed to Spiros L. Blackburn; spiros.blackburn@neurosurgery.ufl.edu

Received 1 January 2014; Accepted 30 January 2014; Published 1 April 2014

Academic Editor: Moneeb Ehtesham

Copyright (C) 2014 Spiros L. Blackburn et al. This is an open access article distributed under the Creative Commons Attribution License, which permits unrestricted use, distribution, and reproduction in any medium, provided the original work is properly cited.

\begin{abstract}
Introduction. The best treatment for unruptured middle cerebral artery (MCA) aneurysms is unclear. We perform a meta-analysis of recent publications to evaluate the results of unruptured MCA aneurysms treated with surgical clipping and endovascular coiling. Methods. A PubMed search for articles published between January 2004 and November 2013 was performed. The R statistical software package was used to create a random effects model for each desired incidence rate. Cochran's $Q$ test was used to evaluate possible heterogeneity among the rates observed in each study. Results. A total of 1891 unruptured MCA aneurysms, 1052 clipped and 839 coiled, were included for analysis. The complete occlusion rate at 6-9 months mean follow-up was $95.5 \%$ in the clipped group and $67.8 \%$ in the coiled group $(P<0.05)$. The periprocedural thromboembolism rate in the clipping group was $1.8 \%$ compared with $10.7 \%$ in the aneurysms treated by coiling $(P<0.05)$. The recanalization rate was $0 \%$ for clipping and $14.3 \%$ for coiling $(P=0.05)$. Modified Rankin scores of $0-2$ were obtained in $98.9 \%$ of clipped patients compared to $95.5 \%$ of coiled (NS). Conclusions. This review weakly supports clipping as the preferred treatment of unruptured MCA aneurysms. Clinical outcomes did not differ significantly between the two groups.
\end{abstract}

\section{Introduction}

Endovascular coiling has emerged as an option in the management of intracranial aneurysms that traditionally have been treated through open surgical clipping [1]. In the United States, the endovascular management of intracranial aneurysms continues to increase $[2,3]$. To support this trend, growing literature is demonstrating low complication rates, durable treatment, and outcomes competitive with surgical results $[1,2,4-7]$.

Unlike aneurysms in other locations, the unruptured middle cerebral artery (MCA) aneurysm has several characteristics favoring surgical treatment. This includes superficial location, a familiar surgical approach, easy proximal control at the supraclinoid carotid, and minimal perforator vessels.
In contrast, endovascular therapy can be somewhat more difficult in this location due to the small parent vessels, difficulty with obtaining adequate working projection views, and incorporation of branch vessels in the aneurysm. However, the endovascular management of aneurysms has evolved, and coiling of unruptured MCA aneurysms is considered an appropriate alternative to clipping for some aneurysms [8].

As the trend for endovascular management of aneurysms has grown to incorporate MCA aneurysms, recent literature has emerged to promote the surgical option as the preferred option $[9,10]$. The aim of this systematic review and metaanalysis is to compare the contemporary outcome and complication rates of clipping and coiling of unruptured MCA aneurysms. 


\section{Materials and Methods}

2.1. Search Strategy. The online database PubMed was used to perform a search of the literature between January 2004 and November 2013. The following search terms were used: (1) middle cerebral artery, (2) aneurysm, (3) coil, (4) coiling, (5) endovascular, (6) surgery, and (7) clipping. The following search string was entered into PubMed: (1) AND (2) AND ((3 OR 4 OR 5) OR (6 OR 7)).

Recently, the presented abstract by Kadkhodayan et al. [11] was also included in the endovascular group. This series, which met the rest of the inclusion criteria, was included because of its size and trial period concurrent with the other included studies.

2.2. Eligibility Criteria. The studies were evaluated for inclusion based on the following guidelines: (1) studies had to be consecutive case series on the treatment of MCA aneurysms using either surgical or endovascular approaches, (2) studies had to report whether treated aneurysms were unruptured or ruptured, (3) studies that examined both unruptured and ruptured aneurysms had to at least report unruptured data independent of the ruptured data, and (4) studies that examined unruptured intracranial aneurysms as aroup had to report MCA aneurysm data independently. Case reports and systematic reviews were not eligible for inclusion. Studies reporting two or less MCA aneurysms were not in English and those exclusively reporting on fusiform, mycotic, or giant aneurysms were also excluded. The included studies were then further examined to ensure that outcome data were provided specifically for unruptured aneurysms, as some articles that initially discussed unruptured and ruptured aneurysms separately pooled outcome data.

2.3. Data Collection and Analysis. The following variables were then extracted from the included studies: (1) patient demographics; (2) unruptured and total number of aneurysms treated; (3) aneurysm locations; (4) aneurysm sizes; (5) technique and any assistive device used; (6) immediate angiographic occlusion status; (7) intraprocedural and periprocedural complications; (8) delayed angiographic occlusion status; (9) morbidity causes and rates; (10) mortality causes and rates; and (11) clinical status at follow-up. Angiographic results were classified according to Raymond's classification. We considered angiographic finding of a thrombus as a thromboembolism complication regardless of being associated or not with a clinical sequel.

Clinical outcomes were primarily reported as a modified Rankin Score (mRS). For those papers reporting outcomes as Glasgow Outcome Scores (GOS), a GOS of 4-5 was equated to an mRS of $0-2$.

The $\mathrm{R}$ statistical software package (Vienna, Austria, V.3.0.2) was used to create a random effects model for each desired incidence rate. We took the arcsin transformed proportion as the outcome and used the inverse of the variance to weight each observation. We assumed each study came from a random sample of a larger population of similar real and hypothetical studies and used restricted maximum likelihood to estimate the variance among studies. Cochran's
Q test [33] was used to evaluate possible heterogeneity among the rates observed in each study. The variance on the figures as the "estimated total heterogeneity" has been reported along with the $P$ value for Cochran's $Q$. A $P<0.05$ for Cochran's $Q$ indicates significant variation among the study rates, suggesting some degree of noncomparability.

For each particular outcome, we compared the confidence intervals for the estimated rates for clipping and coiling where the CIs did not overlap. We concluded that the rates were significantly different at the 0.05 level and we indicated such cases in the results with " $P<0.05$."

\section{Results}

3.1. Search Results and about Studies. The search returned 1912 articles. Of these 1912 articles, 665 were case reports and 9 were reviews, and all of them were excluded. Of the remaining 1238 articles, 101 pertained specifically to treatment of intracranial aneurysms. Of the 101 studies, 20 did not provide separate unruptured data; 4 provided only ruptured data; 19 did not provide separate MCA data; 24 provided only two or less unruptured MCA aneurysms data; 1 provided fusiform data; 10 were not in English. Thus, our search results yielded a total of 23 published series on the endovascular and surgical treatment of MCA aneurysms.

3.2. Studies. Including the abstract presented by Kadkhodayan et al., a total of 24 studies were included in this systematic review. Eight studies provided data on clipping of unruptured MCA aneurysms. Fifteen studies provided data on coiling of unruptured MCA aneurysms. Only one study provided data on both coiling and clipping of unruptured MCA aneurysms. Not all studies provided details on complications, angiographic outcomes, and clinical outcomes. Thus, data from the systematic review regarding these parameters are based on only a proportion of the overall number of patients included depending on the information provided in the different studies. 19 of the studies were retrospective and 5 of them were prospective (Table 1).

3.3. Demographics. A total of 1891 unruptured MCA aneurysms were included and, of these, 1052 aneurysms were treated by clipping and 839 aneurysms were treated by coiling. In the clipping group, the mean age was 58.2. $27.1 \%$ of patients were males and $72.9 \%$ were females. The average size of aneurysms was $5.7 \mathrm{~mm}$ with $95.1 \%$ of aneurysms being small $(<10 \mathrm{~mm})$ and $4.9 \%$ being large $(10-25 \mathrm{~mm})$. In the coiling group, the mean age was 53.7. Of coiled patients, $32.3 \%$ of patients were males and $67.7 \%$ were females; $84.1 \%$ of aneurysms were small and $15.9 \%$ were large (Table 1). One hundred fourteen aneurysms were treated by stent assisted coiling, and 210 were treated by balloon assisted coiling.

3.4. Immediate Angiographic Outcome. Angiographic results at the end of the procedure were available in 15 studies (887 aneurysms). The complete occlusion rate in the clipping group was $94.5 \%$ compared with $55.5 \%$ in the coiling group. $4.1 \%$ of the treated aneurysms in the clipping group had residual necks compared with $33 \%$ in the coiling group. Only 
TABLE 1: Demographic and angiographic results of clipping and coiling studies.

\begin{tabular}{|c|c|c|c|c|c|c|c|c|}
\hline \multirow{2}{*}{ Study name } & \multirow{2}{*}{$\begin{array}{l}\text { Type of the } \\
\text { study }\end{array}$} & \multirow{2}{*}{$\begin{array}{l}\text { Number of unruptured } \\
\text { MCA aneurysms }\end{array}$} & \multirow{2}{*}{$\begin{array}{l}\text { Mean age } \\
\text { (year) }\end{array}$} & \multirow{2}{*}{$\begin{array}{l}\text { Mean size } \\
(\mathrm{mm})\end{array}$} & \multirow{2}{*}{$\begin{array}{l}\text { Average angiographic } \\
\text { F/U, months }(N)\end{array}$} & \multicolumn{3}{|c|}{ Late angiographic outcome } \\
\hline & & & & & & $\mathrm{R} 1$ & $\mathrm{R} 2$ & R3 \\
\hline \multicolumn{9}{|l|}{ Clipping papers } \\
\hline $\begin{array}{l}\text { Diaz et al., } 2012 \\
{[12]}\end{array}$ & $\mathrm{R}$ & 30 & 57.7 & 5.8 & $6(25)$ & 23 & 0 & 2 \\
\hline $\begin{array}{l}\text { Rodriguez- } \\
\text { Hernandez et } \\
\text { al., } 2013 \text { [9] }\end{array}$ & $\mathrm{R}$ & 261 & 55.3 & - & - & - & - & - \\
\hline $\begin{array}{l}\text { Mori et al., } 2011 \\
{[13]}\end{array}$ & $\mathrm{P}$ & 110 & 62 & 6.7 & - & - & - & - \\
\hline $\begin{array}{l}\text { Van Dijk et al., } \\
2011[10]\end{array}$ & $\mathrm{P}$ & 31 & 52.3 & - & $12(11)$ & 11 & 0 & 0 \\
\hline $\begin{array}{l}\text { Jung et al., } 2011 \\
\text { [14] }\end{array}$ & $\mathrm{R}$ & 19 & 72.11 & $6.8^{*}$ & - & - & - & - \\
\hline $\begin{array}{l}\text { Güresir et al., } \\
2011 \text { [15] }\end{array}$ & $\mathrm{P}$ & 108 & 51 & 6.5 & - & - & - & - \\
\hline $\begin{array}{l}\text { Choi et al., } 2012 \\
{[16]}\end{array}$ & $\mathrm{R}$ & 143 & 57.8 & 4 & $1.5(143)$ & 137 & 3 & 3 \\
\hline $\begin{array}{l}\text { Morgan et al., } \\
2010 \text { [17] }\end{array}$ & $\mathrm{R}$ & 339 & 52.7 & - & - & - & - & - \\
\hline $\begin{array}{l}\text { Maruyama et al., } \\
2013 \text { [18] }\end{array}$ & $\mathrm{R}$ & 11 & 63 & 4.5 & - & - & - & - \\
\hline Total & & 1052 & 58.2 & 5.7 & $6.5(179)$ & 171 & 3 & 5 \\
\hline \multicolumn{9}{|l|}{ Coiling papers } \\
\hline $\begin{array}{l}\text { Ihn et al., } 2013 \\
\text { [19] }\end{array}$ & $\mathrm{R}$ & 7 & 51 & 4.1 & $7(6)$ & 6 & 0 & 0 \\
\hline $\begin{array}{l}\text { Diaz et al., } 2012 \\
{[12]}\end{array}$ & $\mathrm{R}$ & 40 & 57.7 & 7.5 & $11.9(40)$ & 31 & 4 & 5 \\
\hline Jin, 2013 [20] & $\mathrm{R}$ & 42 & 58.6 & $5.2^{*}$ & - & - & - & - \\
\hline Cho, 2012 [21] & $\mathrm{P}$ & 36 & 60 & - & - & - & - & - \\
\hline Fields, 2013 [22] & $\mathrm{R}$ & 22 & 62 & - & $12(18)$ & 12 & 3 & 3 \\
\hline $\begin{array}{l}\text { Kim et al., } 2011 \\
\text { [23] }\end{array}$ & $\mathrm{R}$ & 76 & 59 & 7.8 & - & - & - & - \\
\hline $\begin{array}{l}\text { Vendrell, } 2011 \\
\text { [24] }\end{array}$ & $\mathrm{R}$ & 52 & 52 & - & $14(48)$ & 34 & 6 & 8 \\
\hline $\begin{array}{l}\text { Yang et al., } 2010 \\
{[25]}\end{array}$ & $\mathrm{R}$ & 3 & 49.7 & - & $5(3)$ & 3 & 0 & 0 \\
\hline $\begin{array}{l}\text { Quadros et al., } \\
2007 \text { [26] }\end{array}$ & $\mathrm{R}$ & 26 & 48 & 7.5 & $12.9(24)$ & 8 & 15 & 1 \\
\hline $\begin{array}{l}\text { Iijima et al., } \\
2005 \text { [27] }\end{array}$ & $\mathrm{R}$ & 77 & 49 & 7 & - & - & - & - \\
\hline $\begin{array}{l}\text { Vendrell, } 2009 \\
\text { [28] }\end{array}$ & $\mathrm{R}$ & 71 & 49.9 & 6.1 & - & - & - & - \\
\hline $\begin{array}{l}\text { Lubicz et al., } \\
2006[29]\end{array}$ & $\mathrm{P}$ & 17 & 51.8 & - & - & - & - & - \\
\hline $\begin{array}{l}\text { Kadkhodayan et } \\
\text { al., } 2013 \text { [11] }\end{array}$ & $\mathrm{R}$ & 239 & 56 & 6.3 & $6(107)$ & 71 & 23 & 13 \\
\hline $\begin{array}{l}\text { Yahia et al., } \\
2008 \text { [30] }\end{array}$ & $\mathrm{R}$ & 3 & 53 & 10 & - & - & - & - \\
\hline Gory, 2013 [31] & $\mathrm{P}$ & 90 & 53.2 & 6.4 & - & - & - & - \\
\hline $\begin{array}{l}\text { Doerfler, } 2006 \\
\text { [32] }\end{array}$ & $\mathrm{R}$ & 17 & 47.8 & 6.8 & $6(15)$ & 12 & 2 & 1 \\
\hline $\begin{array}{l}\text { Güresir et al., } \\
2011 \text { [15] }\end{array}$ & $\mathrm{P}$ & 21 & - & - & - & - & - & - \\
\hline Total & & 839 & 53.7 & 6.8 & $9.4(261)$ & 177 & 53 & 31 \\
\hline
\end{tabular}

Note: numbers in parentheses are $n$ of aneurysms in patients who did follow-up; —: not reported. ${ }^{*}$ Approximate. R: retrospective; P: prospective; R: Raymond classification for aneurysmal occlusion; R1: complete; R2: residual neck; R3: residual sac. 
$1.4 \%$ of aneurysms treated by clipping had residual sacs in comparison to $11.5 \%$ of those treated by coiling $(P<0.05)$. Only a small fraction (1.7\%) of unruptured MCA aneurysms could not be coiled while all aneurysms were clipped in the clipping group.

3.5. Procedure Related Complications. Procedural complications for included studies are displayed in Table 2 . The thromboembolism rate in the clipped group was $1.8 \%$ compared with $10.7 \%$ in the aneurysms treated by coiling $(P<0.05)$ (Figure 2). The parent artery occlusion rate was $0.3 \%$ in coiled group and $0.7 \%$ in the clipped group (not statistically significant). There were one TIA in the clipped group $(0.2 \%)$ and 6 in the coiled group (0.9\%) (not statistically significant). The intraoperative rupture rate in aneurysms treated by clipping was $1.3 \%$, compared with $2.5 \%$ in the coiled group (not statistically significant).

3.6. Late Angiographic Follow-Up. Angiographic follow-up results were available in 12 studies (440 aneurysms) (Table 1). The average follow-up period in the clipped group was 6.5 months while the average follow-up period in the coiled group was 9.4 months. The complete occlusion rate in the clipping group was $95.5 \%$ compared with $67.3 \%$ in the coiled group and $1.7 \%$ of aneurysms treated by clipping had residual necks in comparison to $20.3 \%$ in the coiled group. Only $2.8 \%$ of aneurysms treated by clipping had a residual sac in comparison to $11.9 \%$ in the coiled group $(P<0.05)$ (Figure 1). No recanalization was identified with any of the aneurysms treated by clipping. In contrast, the recanalization rate for aneurysms treated by coiling was $14.3 \%(P<0.05)$. In addition, $5.3 \%$ of coiled aneurysms required retreatment in contrast to only one case in the clipped group (not statistically significant).

3.7. Clinical Outcome. The average clinical follow-up period for the clipped group was 11 months and 9.6 months for the coiled group.

A total of 366 patients (125 clipping and 241 coiling) had outcomes reported as mRS linearly. In patients treated with clipping, $97.6 \%$ of patients had an $\mathrm{mRS}$ score of 0 compared to $82.9 \%$ of those treated by coiling. The percentage of patients with an mRS of 1 was $0.8 \%$ and $9.7 \%$, respectively; with an mRS of 2 was $0.5 \%$ and $1.2 \%$, respectively; with mRs of 3 was $0 \%$ and $2.3 \%$, respectively; with an mRS of 4 was $0 \%$ and $2.3 \%$, respectively; and with an mRS of 5 was $0 \%$ for both. There was no statistically significant difference between the two treatments (Table 2).

Clinical outcome was readdressed after dichotomizing mRS into good (mRS 0-2) and poor outcomes (mRS 35). This analysis was performed since a number of papers grouped these outcomes and this allowed a larger data inclusion (733 clipping and 461 coiling). In the clipped group, the percentage of patients with an mRS of $0-2$ was $98.9 \%$ compared to $96.5 \%$ in the coiled group. There was no statistically significant difference between the two groups (Figure 4).
3.8. Morbidity and Mortality. The overall morbidity in the clipping group was $4.6 \%$, while, in the coiling group, it was $15.3 \%(P<0.05)$ (Figure 3). Five out of 999 patients died in the clipped group $(0.5 \%)$, and the mortality rate in the coiled group was $1.2 \%$ (7 deaths in 572 patients).

\section{Discussion}

The emergence of endovascular therapy has revolutionized the management of intracranial aneurysms. For aneurysms in the posterior circulation, endovascular treatment is considered preferable to open surgical clipping in most cases $[34,35]$.

This consensus is not generalizable to all aneurysms and the treatment risks of a particular aneurysm depend on rupture status, anatomical factors, institutional paradigm, and treating physician experience. In the case of unruptured intracranial aneurysms, the endovascular surgeon has the full armamentarium of assist devices and can easily treat even wide neck aneurysms. Despite these additional tools, the management of middle cerebral artery aneurysms is considered to be in favor of surgical treatment by many experts $[9,10,12]$.

We found that the surgical treatment of unruptured MCA aneurysms was associated with similar clinical outcomes to endovascular therapy. In the clipped group, only 2 papers reported outcomes of $\mathrm{mRS}$ in all categories, compared to 9 papers in the coiled group (125 clipped versus 257 coiled) [11-13, 19, 23, 25-27, 29, 30]. In many papers, outcomes were grouped into "good" or "poor" based on mRS or GOS criteria. When these results were included, the number of patients increased to 733 in the clip group and 461 in the coil group. The clinical outcomes were slightly better in clipping group when both analyses were performed but not statistically different (Figure 4). The largest difference in outcomes was in the mRS 0 and mRS 1 categories; however, since many papers only looked at mRS 0-2 as a group, the sensitivity to detect a difference in the mRS 0 to mRS 1 outcome was diluted.

When comparing clinical outcomes of coiled MCA aneurysms to aneurysms in other locations, the MCA location confers a slightly higher procedural risk. For the coiling group in our analysis, $83 \%$ (213/257, mean follow-up of 9.6 months) were an mRS 0, and an unfavorable (mRS 35) outcome was seen in $3.4 \%$. In comparison, two large retrospective reviews with coiling of 916 small unruptured aneurysms, 910 (99\%) patients had an mRS of 0 at the last follow-up, a better result than that of our MCA coiling group $[36,37]$. This would suggest that endovascular treatment of MCA aneurysms has a higher complication rate than aneurysms in other locations.

The prospective ATENA study, reporting immediate clinical outcome of 649 patients harboring 739 unruptured intracranial aneurysms treated by endovascular coiling, indicated a change of mRS in $11(1.7 \%)$ patients at one month and a mortality of 9 (1.4\%) [38]. The ATENA study included 218 MCA aneurysms, and in subgroup analysis, the MCA location had the highest rate of thromboembolic complications compared to ACA, ICA, posterior circulation (9.6\% versus 


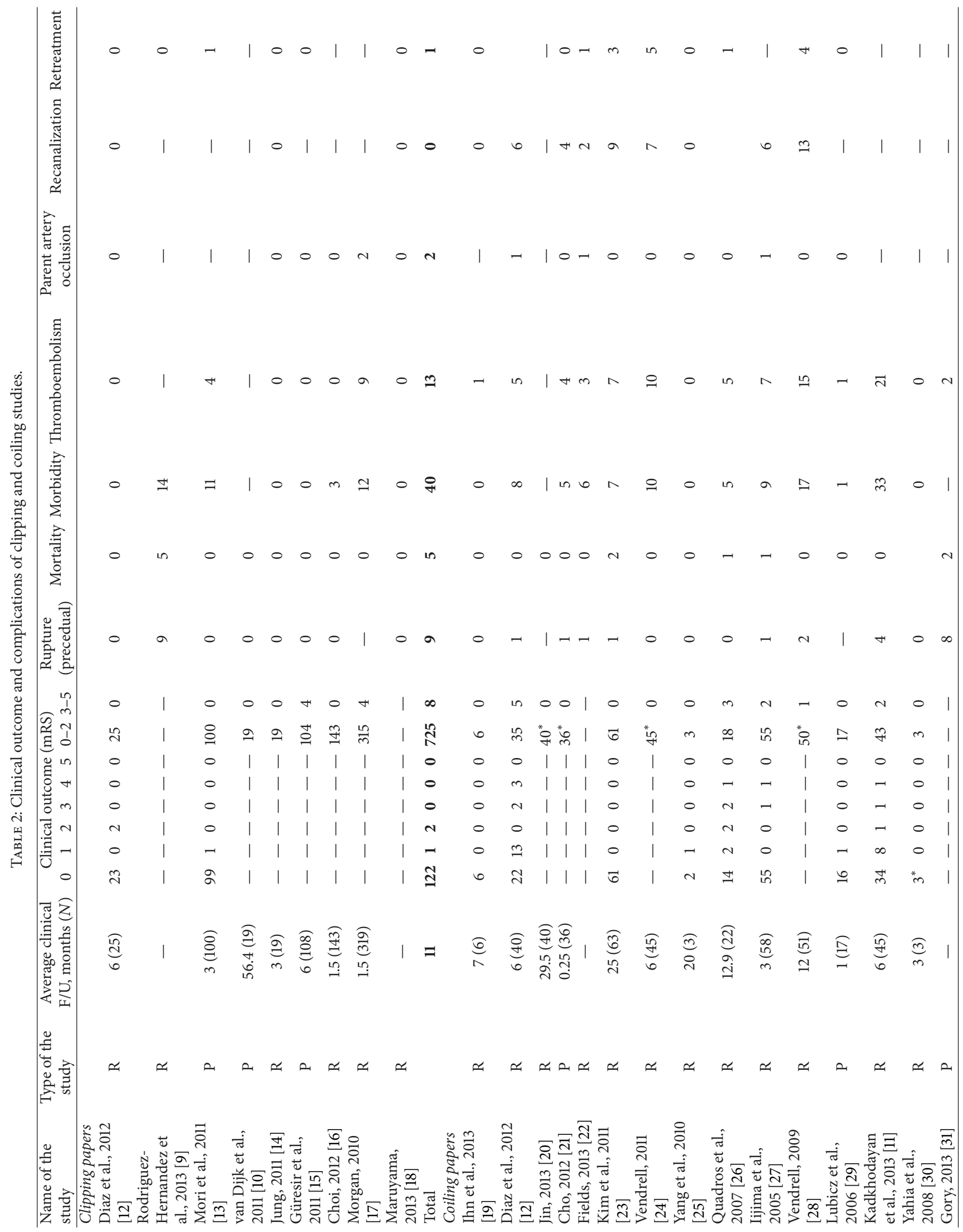




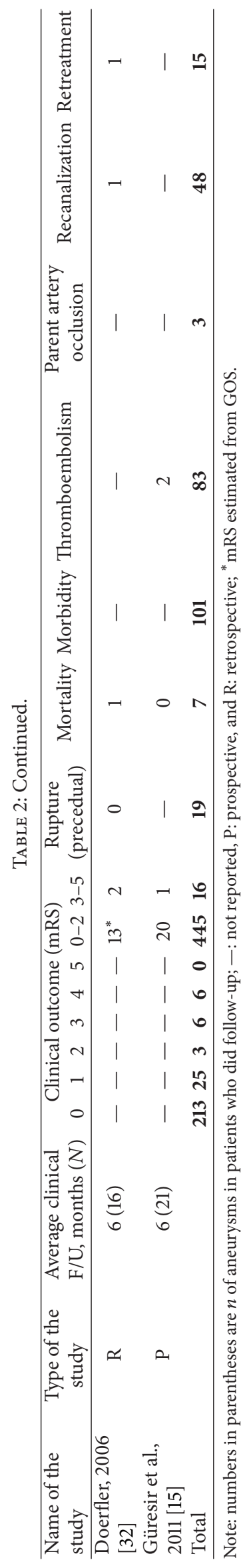


Clipping: long-term complete occlusion

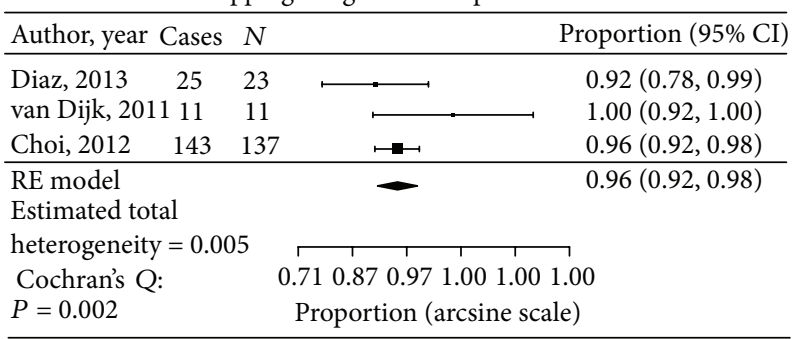

(a)

Coiling: long-term complete occlusion

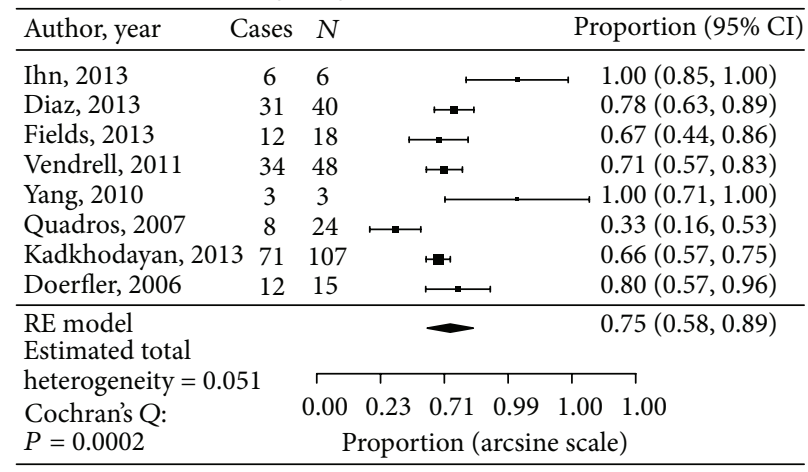

(b)

Coiling: long-term neck remnant

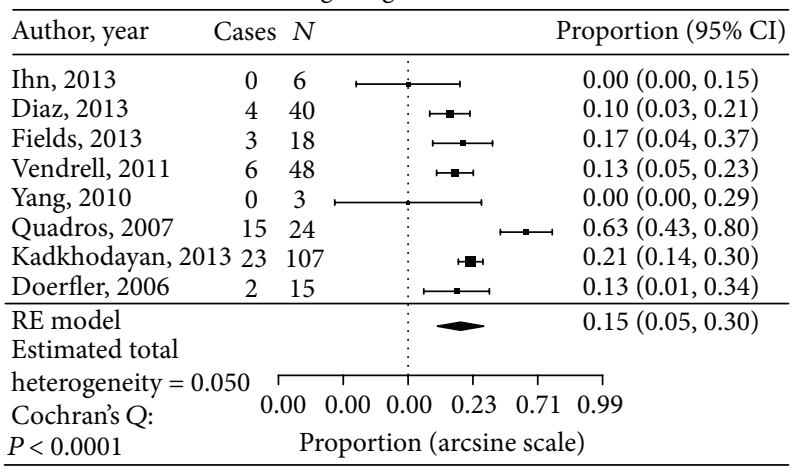

(d)

(c)

Coiling: long-term residual sac

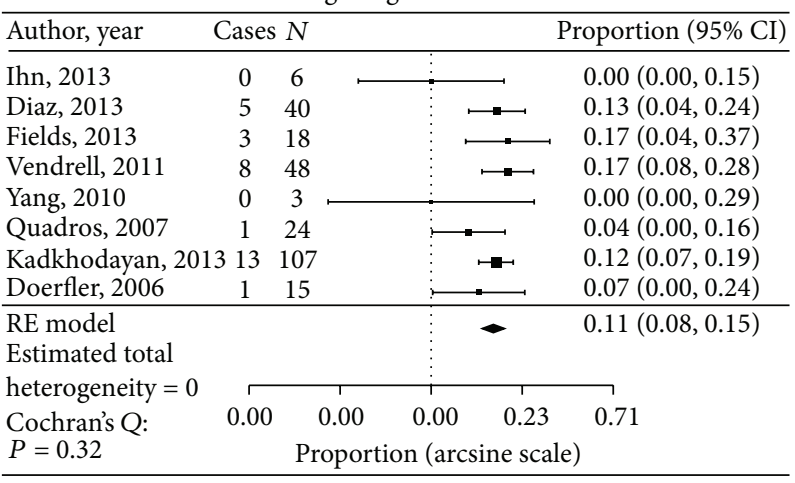

(f)

FIGURE 1: Data analysis of long-term angiographic outcome in both clipped and coiled groups.

$8.8 \%$ versus $4.6 \%$ versus $3.3 \%$ ), and intraoperative rupture ( $4.1 \%$ versus $2.2 \%$ versus $1.9 \%$ versus $0.0 \%$ ) [38].

In a meta-analysis of endovascular treatment of intracranial aneurysms by Naggara et al., an unfavorable outcome $(\mathrm{mRS}>2)$ was seen in only $4.8 \%(189 / 5044)$ of patients [39]. This is very similar to our results for coiling of MCA aneurysms $(3.4 \%, 16 / 461)$. Although unfavorable outcomes may be similar, the majority of complications in our series resulted in an mRS of 1 or 2 .

A more deliberate comparison of outcomes was performed in a recently published Japanese registry of unruptured intracranial aneurysms [40]. Overall outcomes for 4573 procedures were mRS 0 in $91.7 \%$, mRS 1 in $4.5 \%$, and $\mathrm{mRS} 2$ in $1.8 \%$. Less than $2 \%$ of all aneurysms were mRS $3-5$ at one month. Only 6.3\% (301) of all aneurysms treated were MCA aneurysms. These outcomes highlight that the difference in outcomes is primarily with mRS of 0 and 1 . Compared to our meta-analysis, the results for this series were better than those published for MCA aneurysms alone (mRS 0, 91.7\% versus mRS 0, 83\%, resp.).

Angiographic results were better reported in the coiling group than in the clipping group (261 versus 179 patients) and follow-up was for a longer period (9.4 months versus 6.5 months). With these limitations in mind, clipping offered a 


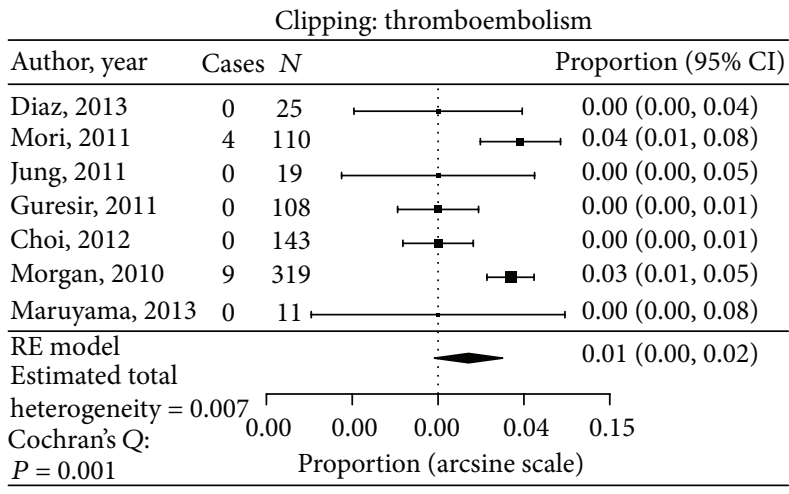

(a)

\begin{tabular}{|c|c|c|c|c|}
\hline \multicolumn{5}{|c|}{ Coiling: thromboembolism } \\
\hline \multirow{2}{*}{$\begin{array}{l}\text { Author, year } \\
\text { Ihn, } 2013\end{array}$} & \multicolumn{2}{|c|}{ Cases $N$} & \multicolumn{2}{|r|}{ Proportion $(95 \% \mathrm{CI})$} \\
\hline & 1 & 7 & & $0.14(0.00,0.47)$ \\
\hline Diaz, 2013 & 52 & 40 & $\longmapsto$ & $0.13(0.04,0.24)$ \\
\hline Cho, 2012 & 43 & 36 & $\longmapsto$ & $0.11(0.03,0.23)$ \\
\hline Fields, 2013 & 32 & 22 & $\longmapsto$ & $0.14(0.03,0.31)$ \\
\hline Kim, 2011 & 77 & 76 & $\mapsto$ & $0.09(0.04,0.17)$ \\
\hline Vendre & 105 & 50 & $\longmapsto$ & \\
\hline Yang, 2010 & 0 & 3 & & 0.00 \\
\hline Quad & 52 & 26 & $\longmapsto$ & \\
\hline Iijir & 77 & 77 & $\mapsto$ & 0.0 \\
\hline Vendrell, 2009 & 15 & 67 & $\longmapsto$ & $0.22(0.13,0.33)$ \\
\hline Lubicz, 2006 & 11 & 17 & $\longrightarrow$ & $0,0.22)$ \\
\hline Kadkhodayan, 2013 & 3212 & 239 & 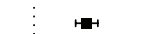 & $0.09(0.06,0.13)$ \\
\hline Yahia, 2007 & 0 & 3 & & $0.00(0.00,0.29)$ \\
\hline Go & 25 & 90 & $\mapsto$ & $0,0.06)$ \\
\hline Guresir, 2011 & 22 & 21 & $\longmapsto$ & $0.10(0.01,0.25)$ \\
\hline $\begin{array}{l}\text { RE model } \\
\text { Estimated total }\end{array}$ & & & - & $0.11(0.07,0.15)$ \\
\hline heterogeneity = & & & & \\
\hline Cochran's Q & & & 0.00 & 0.71 \\
\hline$P=0.012$ & & Propol & (arcsine s) & \\
\hline
\end{tabular}

(b)

FIgURE 2: Data analysis of thromboembolism complication in both clipped and coiled groups.

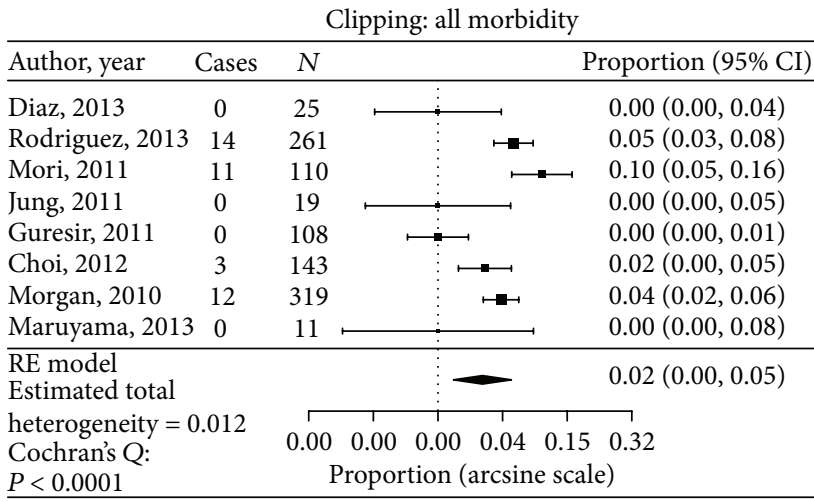

(a)
Coiling: all morbidity

\begin{tabular}{|c|c|c|c|c|}
\hline Author, year & Cases & $N$ & & Proportion $(95 \% \mathrm{CI})$ \\
\hline Ihn, 2013 & 0 & 7 & 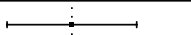 & $0.00(0.00,0.13)$ \\
\hline Diaz, 2013 & 8 & 40 & $\longmapsto$ & $0.20(0.09,0.34)$ \\
\hline Cho, 2012 & 5 & 36 & 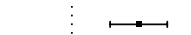 & $0.14(0.05,0.27)$ \\
\hline Fields, 2013 & 6 & 22 & $\longmapsto$ & $0.27(0.11,0.47)$ \\
\hline Kim, 2011 & 7 & 76 & $\mapsto$ & $0.09(0.04,0.17)$ \\
\hline Vendrell, 2011 & 10 & 50 & $\longmapsto$ & $0.20(0.10,0.32)$ \\
\hline Yang, 2010 & 0 & 3 & — & $0.00(0.00,0.29)$ \\
\hline Quadros, 2007 & 5 & 26 & $\longmapsto$ & $0.19(0.07,0.36)$ \\
\hline Iijima, 2005 & 9 & 77 & $\longmapsto$ & $0.12(0.06,0.20)$ \\
\hline Vendrell, 2009 & 17 & 67 & $\longmapsto$ & $0.25(0.16,0.36)$ \\
\hline Lubicz, 2006 & 1 & 17 & $\longrightarrow$ & $0.06(0.00,0.22)$ \\
\hline Kadkhodayan, 2013 & 333 & 239 & -1 & $0.14(0.10,0.18)$ \\
\hline $\begin{array}{l}\text { RE model } \\
\text { Estimated total }\end{array}$ & & & - & $0.15(0.11,0.19)$ \\
\hline heterogeneity $=0.00$ & 030.00 & & & \\
\hline $\begin{array}{l}\text { Cochran's } Q: \\
P=0.05\end{array}$ & \multicolumn{4}{|c|}{ 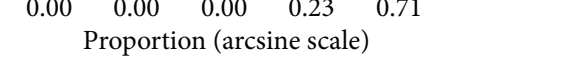 } \\
\hline
\end{tabular}

(b)

FIGURE 3: Data analysis of all morbidity cases in both clipped and coiled groups.

better angiographic result. It is not surprising that clipping yields improved angiographic results; however, incompletely coiled aneurysms likely have a very low risk of hemorrhage [41]. In the coiling group, Raymond's classes I and II were achieved in 230/261 aneurysms (88\%). This result is not to be dismissed, and on top of the already low rupture risk of unruptured intracranial aneurysms, this may be adequate for protection though long-term studies are needed.

Like clinical outcomes, angiographic outcome in MCA aneurysms compared to other locations is also slightly less favorable. Im et al. [37], reporting on a series of 435 small unruptured aneurysms, were able to achieve complete or near complete occlusion in $95 \%$ of all aneurysms at treatment. Follow-up in 358/435 patients was performed at a mean of 14.2 months with 337 (94.1\%) aneurysms remaining stable and $21(5.9 \%)$ aneurysms recurring. Only 6 aneurysms were retreated. The majority of aneurysms were in the anterior circulation 390/435, and only 46/435 were MCA aneurysms.

Oishi et al. [36], reporting on 500 small unruptured intracranial aneurysms, were able to achieve complete or near complete occlusion of $79 \%$ (381/481) of aneurysms at treatment. Follow-up imaging was obtained in 427 aneurysms at an average of 31 months. Eighty-three percent (355/427) remained stable or showed progressive occlusion while recurrence occurred in $17 \%$ (72/427). Interestingly, $81 \mathrm{MCA}$ aneurysms were attempted of which $9 / 81$ (11.1\%) were treatment failures, the highest failure rate of any location. The overall retreatment rate was $2.9 \%(14 / 481)$.

These studies seem to be in contrast to the ATENA study which showed a much lower rate of coil occlusion for all locations, complete in 63\% (437/694), neck remnant in $22.5 \%(156 / 694)$, and aneurysm remnant $14.6 \%(101 / 694)$ 


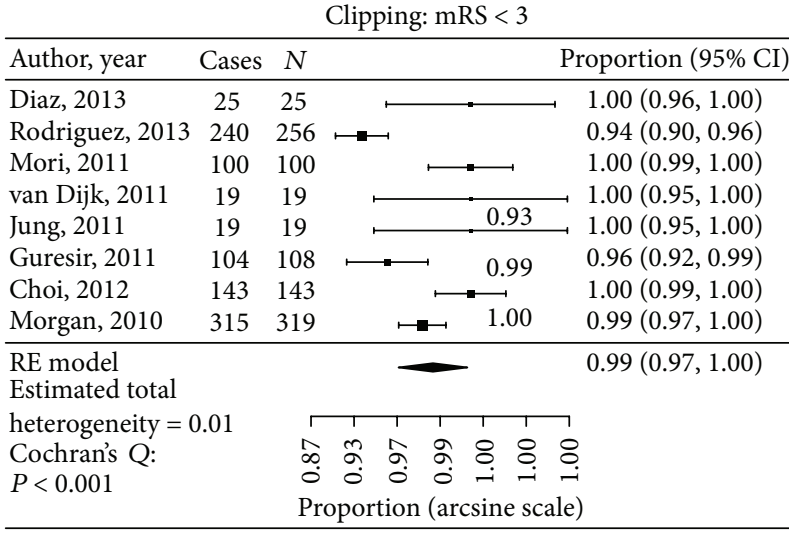

(a)

\begin{tabular}{|c|c|c|c|c|}
\hline \multicolumn{5}{|c|}{ Coiling: $\mathrm{mRS}<3$} \\
\hline Author, year & Cases & $N$ & & Proportion $(95 \% \mathrm{CI})$ \\
\hline Ihn, 2013 & 6 & 6 & & $1.00(0.85,1.00)$ \\
\hline Diaz, 2013 & 35 & 40 & $\longmapsto$ & $0.88(0.76,0.96)$ \\
\hline Jin, 2013 & 40 & 40 & $\longmapsto$ & $1.00(0.98,1.00)$ \\
\hline Cho, 2012 & 36 & 36 & $\longmapsto$ & $1.00(0.97,1.00)$ \\
\hline $\mathrm{Kim}, 2$ & 61 & 61 & $\mapsto$ & $1.00(0.98,1.00)$ \\
\hline Vendre & 45 & 45 & $\longmapsto$ & $98,1.00)$ \\
\hline Yang, 2010 & 3 & 3 & & $1.00(0.71,1.00)$ \\
\hline 2007 & 18 & 21 & $\longmapsto$ & $0.86(0.68,0.97)$ \\
\hline & 55 & 57 & $\mapsto$ & 0.9 \\
\hline Vendrell, 2009 & 50 & 51 & $\mapsto$ & $0.98(0.92,1.00)$ \\
\hline Lubicz & 17 & 17 & $\longmapsto$ & $94,1.00)$ \\
\hline dayan, 201 & 1343 & 45 & $\longmapsto$ & $0.96(0.88,1.00)$ \\
\hline & 3 & & & $1.00(0.71,1.00)$ \\
\hline Do & 13 & 15 & $=$ & $0.87(0.66,0.99)$ \\
\hline Guresir, 2011 & 20 & 21 & $\longmapsto$ & $0.95(0.82,1.00)$ \\
\hline $\begin{array}{l}\text { RE model } \\
\text { Estimated total } \\
\text { heterogeneity }=\end{array}$ & & & - & $0.98(0.95,1.00)$ \\
\hline Cochran's & 0.23 & & 0.99 & 1.00 \\
\hline$P-$ & & & $\mathrm{n}(\operatorname{arcs}$ & \\
\hline
\end{tabular}

(b)

FIGURE 4: Data analysis of clinical outcome in both clipped and coiled groups.

[42]. This difference in reporting is likely accounted for by the prospective and independent review of imaging by the ATENA investigators. An independent review was performed in only three of the coiling series presented $[23,25,26,39]$.

One argument for endovascular therapy is that it is more comfortable and results in a shorter hospital stay [43-45]. This is a reasonable discerning factor when angiographic and clinical outcomes are similar and has led to the adoption of a "coil first" preference at many centers. For MCA aneurysms, obliteration is clearly better following surgical clipping than endovascular coiling. Clinical outcome between the two groups is not statistically different in this meta-analysis; however, additional publications with $\mathrm{mRS}$ data in the 0,1 , and 2 categories are needed for clarification. There does appear to be a trend toward higher complications with endovascular treatment of MCA aneurysms and worse clinical outcome compared to the endovascular treatment of aneurysms in other locations as well as clipping of MCA aneurysms. As a result, we favor open surgical treatment of unruptured MCA aneurysms despite the longer hospital stay and increased short-term expense. This recommendation will certainly require reassessment as more literature emerges for outcomes after endovascular treatment of MCA aneurysms.

The limitations of this review are significant. First, the patients included in the analysis were from both prospective and retrospective studies, and therefore our conclusions are subject to limitations inherent to the individual studies included. Most importantly, core lab adjudication for angiographic and clinical outcomes was not a prerequisite for inclusion in our study. Almost certainly, this results in overestimation of good angiographic results and good clinical outcomes in both groups. In addition, a portion of the included patients is from a series that has yet to be published. Lastly, when single arm studies are reviewed, a large selection bias exists. This bias likely favors the endovascular group since unfavorable aneurysms will be treated surgically.

\section{Conclusions}

Based on the results of this meta-analysis, the clinical outcomes following endovascular coiling of MCA aneurysms are not statistically different from clipping. Although there is a trend for better clinical outcome with surgery, the analysis is limited by a small amount of published data for both groups in the last 10 years. The endovascular treatment of MCA aneurysms may be associated with a higher risk than that of aneurysms in other locations.

\section{Conflict of Interests}

The authors declare that there is no conflict of interests regarding the publishing of this paper.

\section{Acknowledgment}

The authors would like to acknowledge Dan Neal, M.S., for his assistance with the statistical analysis.

\section{References}

[1] A. J. Molyneux, R. S. Kerr, J. Birks et al., "Risk of recurrent subarachnoid haemorrhage, death, or dependence and standardised mortality ratios after clipping or coiling of an intracranial aneurysm in the International Subarachnoid Aneurysm Trial (ISAT): long-term follow-up," The Lancet Neurology, vol. 8, no. 5, pp. 427-433, 2009.

[2] W. Brinjikji, A. A. Rabinstein, D. M. Nasr, G. Lanzino, D. F. Kallmes, and H. J. Cloft, "Better outcomes with treatment by coiling relative to clipping of unruptured intracranial aneurysms in the United States, 2001-2008," American Journal of Neuroradiology, vol. 32, no. 6, pp. 1071-1075, 2011.

[3] A. I. Qureshi, G. Vazquez, N. Tariq, M. F. K. Suri, K. Lakshminarayan, and G. Lanzino, "Impact of International Subarachnoid Aneurysm Trial results on treatment of ruptured intracranial 
aneurysms in the United States: clinical article," Journal of Neurosurgery, vol. 114, no. 3, pp. 834-841, 2011.

[4] J. S. McDonald, R. J. McDonald, J. Fan, D. F. Kallmes, G. Lanzino, and H. J. Cloft, "Comparative effectiveness of unruptured cerebral aneurysm therapies: propensity score analysis of clipping versus coiling," Stroke; A Journal of Cerebral Circulation, vol. 44, no. 4, pp. 988-994, 2013.

[5] W. Brinjikji, A. A. Rabinstein, G. Lanzino, D. F. Kallmes, and H. J. Cloft, "Patient outcomes are better for unruptured cerebral aneurysms treated at centers that preferentially treat with endovascular coiling: a study of the national inpatient sample 2001-2007," American Journal of Neuroradiology, vol. 32, no. 6, pp. 1065-1070, 2011.

[6] F. Proust, O. Martinaud, E. Gérardin et al., "Quality of life and brain damage after microsurgical clip occlusion or endovascular coil embolization for ruptured anterior communicating artery aneurysms: neuropsychological assessment-clinical article," Journal of Neurosurgery, vol. 110, no. 1, pp. 19-29, 2009.

[7] H. Li, R. Pan, H. Wang et al., "Clipping versus coiling for ruptured intracranial aneurysms: a systematic review and metaanalysis," Stroke; A Journal of Cerebral Circulation, vol. 44, no. 1, pp. 29-37, 2013.

[8] W. Brinjikji, G. Lanzino, H. J. Cloft, A. Rabinstein, and D. F. Kallmes, "Endovascular treatment of middle cerebral artery aneurysms: a systematic review and single-center series," Neurosurgery, vol. 68, no. 2, pp. 397-402, 2011.

[9] A. Rodriguez-Hernandez, M. E. Sughrue, S. Akhavan, J. Habdank-Kolaczkowski, and M. T. Lawton, "Current management of middle cerebral artery aneurysms: surgical results with a "clip first" policy," Neurosurgery, vol. 72, no. 3, pp. 415-427, 2013.

[10] J. M. C. van Dijk, R. J. M. Groen, M. Ter Laan, J. R. Jeltema, J. J. A. Mooij, and J. D. M. Metzemaekers, "Surgical clipping as the preferred treatment for aneurysms of the middle cerebral artery," Acta Neurochirurgica, vol. 153, no. 11, pp. 2111-2117, 2011.

[11] Y. Kadkhodayan, J. E. Delgado Almandoz, J. L. Fease et al., "Endovascular treatment of middle cerebral artery aneurysms: a 16-year single-center experience," in Proceedings of the 10th Annual Meeting of the Society of NeuroInterventional Surgery, Miami, Fla, USA, July 29, 2013.

[12] O. M. Diaz, L. Rangel-Castilla, S. Barber, R. C. Mayo, R. Klucznik, and Y. J. Zhang, "Middle cerebral artery aneurysms: a single-center series comparing endovascular and surgical treatment," World Neurosurgery, 2012.

[13] K. Mori, T. Esaki, T. Yamamoto, and Y. Nakao, "Individualized pterional keyhole clipping surgery based on a preoperative three-dimensional virtual osteotomy technique for unruptured middle cerebral artery aneurysm," Minimally Invasive Neurosurgery, vol. 54, no. 5-6, pp. 207-213, 2011.

[14] Y. J. Jung, J. S. Ahn, E. S. Park, H. Kwon do, B. D. Kwun, and C. J. Kim, "Surgical results of unruptured intracranial aneurysms in the elderly: single center experience in the past ten years," Journal of Korean Neurosurgical Society, vol. 49, no. 6, pp. 329333, 2011.

[15] E. Güresir, P. Schuss, J. Berkefeld, H. Vatter, and V. Seifert, "Treatment results for complex middle cerebral artery aneurysms. A prospective single-center series," Acta Neurochirurgica, vol. 153, no. 6, pp. 1247-1252, 2011.

[16] S. W. Choi, J. S. Ahn, J. C. Park, H. Kwon do, B. D. Kwun, and C. J. Kim, "Surgical treatment of unruptured intracranial middle cerebral artery aneurysms: angiographic and clinical outcomes in 143 aneurysms," Journal of Cerebrovascular and Endovascular Neurosurgery, vol. 14, no. 4, pp. 289-294, 2012.

[17] M. K. Morgan, W. Mahattanakul, A. Davidson, and J. Reid, "Outcome for middle cerebral artery aneurysm surgery," Neurosurgery, vol. 67, no. 3, pp. 755-761, 2010.

[18] K. Maruyama, H. Kurita, R. Yamaguchi, A. Noguchi, and Y. Shiokawa, "One-stage clipping of bilateral middle cerebral artery aneurysms via the bilateral pterional keyhole approach," Neurologia Medico-Chirurgica, vol. 53, no. 3, pp. 148-152, 2013.

[19] Y. K. Ihn, B. M. Kim, S. H. Suh, D. J. Kim, and D. I. Kim, "Coilprotected embolization technique for a branch-incorporated aneurysm," Korean Journal of Radiology, vol. 14, no. 2, pp. 329336, 2013.

[20] S. C. Jin, O. K. Kwon, C. W. Oh et al., "Simple coiling using single or multiple catheters without balloons or stents in middle cerebral artery bifurcation aneurysms," Neuroradiology, vol. 55, no. 3, pp. 321-326, 2013.

[21] Y. D. Cho, H. S. Kang, J. E. Kim et al., "Microcatheter looping technique for coil embolization of complex configuration middle cerebral artery aneurysms," Neurosurgery, vol. 71, no. 6, pp. 1185-1191, 2012.

[22] J. D. Fields, L. Brambrink, A. Dogan et al., "Stent assisted coil embolization of unruptured middle cerebral artery aneurysms," Journal of Neurointerventional Surgery, vol. 5, no. 1, pp. 15-19, 2013.

[23] B. M. Kim, D. I. Kim, S. I. Park, D. J. Kim, S. H. Suh, and Y. S. Won, "Coil embolization of unruptured middle cerebral artery aneurysms," Neurosurgery, vol. 68, no. 2, pp. 346-353, 2011.

[24] J.-F. Vendrell, V. Costalat, H. Brunel, C. Riquelme, and A. Bonafe, "Stent-assisted coiling of complex middle cerebral artery aneurysms: initial and midterm results," American Journal of Neuroradiology, vol. 32, no. 2, pp. 259-263, 2011.

[25] P. Yang, J. Liu, Q. Huang et al., "Endovascular treatment of wideneck middle cerebral artery aneurysms with stents: a review of 16 cases," American Journal of Neuroradiology, vol. 31, no. 5, pp. 940-946, 2010.

[26] R. S. Quadros, S. Gallas, R. Noudel, P. Rousseaux, and L. Pierot, "Endovascular treatment of middle cerebral artery aneurysms as first option: a single center experience of 92 aneurysms," American Journal of Neuroradiology, vol. 28, no. 8, pp. 15671572, 2007.

[27] A. Iijima, M. Piotin, C. Mounayer, L. Spelle, A. Weill, and J. Moret, "Endovascular treatment with coils of 149 middle cerebral artery berry aneurysms," Radiology, vol. 237, no. 2, pp. 611-619, 2005.

[28] J.-F. Vendrell, N. Menjot, V. Costalat et al., "Endovascular treatment of 174 middle cerebral artery aneurysms: clinical outcome and radiologic results at long-term follow-up," Radiology, vol. 253, no. 1, pp. 191-198, 2009.

[29] B. Lubicz, J. Graca, M. Levivier et al., "Endovascular treatment of middle cerebral artery aneurysms," Neurocritical Care, vol. 5, no. 2, pp. 93-101, 2006.

[30] A. M. Yahia, V. Gordon, J. Whapham, A. Malek, J. Steel, and R. D. Fessler, "Complications of Neuroform stent in endovascular treatment of intracranial aneurysms," Neurocritical Care, vol. 8, no. 1, pp. 19-30, 2008.

[31] B. Gory, A. Rouchaud, S. Saleme et al., "Endovascular treatment of middle cerebral artery aneurysms for 120 nonselected patients: a prospective Cohort Study," American Journal of Neuroradiology, 2013. 
[32] A. Doerfler, I. Wanke, S. L. Goericke et al., "Endovascular treatment of middle cerebral artery aneurysms with electrolytically detachable coils," American Journal of Neuroradiology, vol. 27, no. 3, pp. 513-520, 2006.

[33] L. V. Hedges and I. Olkin, Olkin.Statistical Methods for MetaAnalysis, Academic Press, San Diego, Calif, USA, 1985.

[34] R. C. Heros, "International subarachnoid aneurysm trial analysis," Journal of Neurosurgery, vol. 108, no. 3, pp. 433-435, 2008.

[35] D. O. Wiebers, "Unruptured intracranial aneurysms: natural history, clinical outcome, and risks of surgical and endovascular treatment," The Lancet, vol. 362, no. 9378, pp. 103-110, 2003.

[36] H. Oishi, M. Yamamoto, T. Shimizu, K. Yoshida, and H. Arai, "Endovascular therapy of 500 small asymptomatic unruptured intracranial aneurysms," American Journal of Neuroradiology, vol. 33, no. 5, pp. 958-964, 2012.

[37] S.-H. Im, M. H. Han, O.-K. Kwon et al., "Endovascular coil embolization of 435 small asymptomatic unruptured intracranial aneurysms: procedural morbidity and patient outcome," American Journal of Neuroradiology, vol. 30, no. 1, pp. 79-84, 2009.

[38] L. Pierot, L. Spelle, and F. Vitry, "Immediate clinical outcome of patients harboring unruptured intracranial aneurysms treated by endovascular approach: results of the ATENA study," Stroke; A Journal of Cerebral Circulation, vol. 39, no. 9, pp. 2497-2504, 2008.

[39] O. N. Naggara, P. M. White, F. Guilbert, D. Roy, A. Weill, and J. Raymond, "Endovascular treatment of intracranial unruptured aneurysms: systematic review and meta-analysis of the literature on safety and efficacy," Radiology, vol. 256, no. 3, pp. 887$897,2010$.

[40] T. Shigematsu, T. Fujinaka, T. Yoshimine et al., "Endovascular therapy for asymptomatic unruptured intracranial aneurysms: JR-NET and JR-NET2 findings," Stroke; A Journal of Cerebral Circulation, vol. 44, no. 10, pp. 2735-2742, 2013.

[41] J. D. Schaafsma, M. E. Sprengers, W. J. van Rooij et al., "Longterm recurrent subarachnoid hemorrhage after adequate coiling versus clipping of ruptured intracranial aneurysms," Stroke; A Journal of Cerebral Circulation, vol. 40, no. 5, pp. 1758-1763, 2009.

[42] L. Pierot, L. Spelle, F. Vitry et al., "Immediate anatomic results after the endovascular treatment of unruptured intracranial aneurysms: analysis of the ATENA series," American Journal of Neuroradiology, vol. 31, no. 1, pp. 140-144, 2010.

[43] B. L. Hoh, Y.-Y. Chi, M. A. Dermott, P. J. Lipori, and S. B. Lewis, "The effect of coiling versus clipping of ruptured and unruptured cerebral aneurysms on length of stay, hospital cost, hospital reimbursement, and surgeon reimbursement at the University of Florida," Neurosurgery, vol. 64, no. 4, pp. 614-621, 2009.

[44] B. L. Hoh, Y.-Y. Chi, M. F. Lawson, J. Mocco, and F. G. Barker, "Length of stay and total hospital charges of clipping versus coiling for ruptured and unruptured adult cérébral aneurysms in the nationwide inpatient sample database 2002 to 2006," Stroke; A Journal of Cerebral Circulation, vol. 41, no. 2, pp. 337342, 2010.

[45] S. P. Lad, R. Babu, M. S. Rhee et al., "Long-term economic impact of coiling vs clipping for unruptured intracranial aneurysms," Neurosurgery, vol. 72, no. 6, pp. 1000-1003, 2013. 


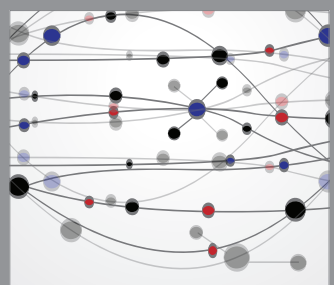

The Scientific World Journal
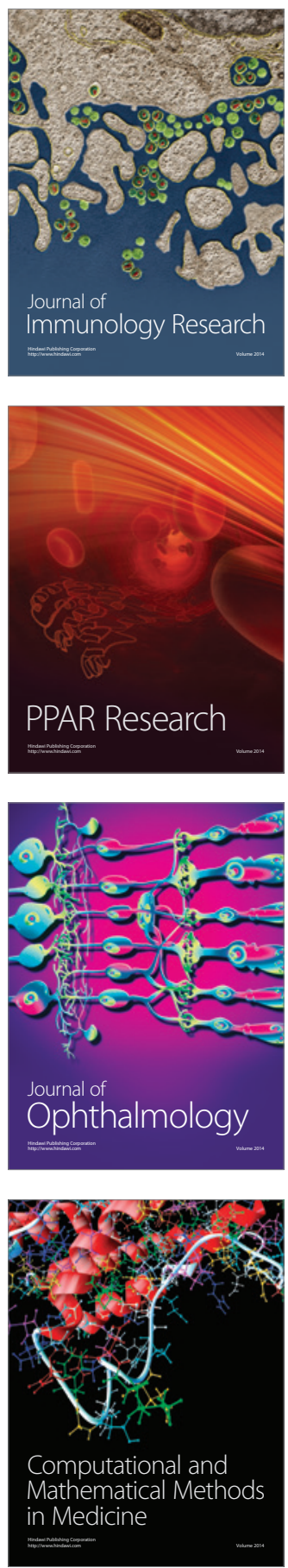

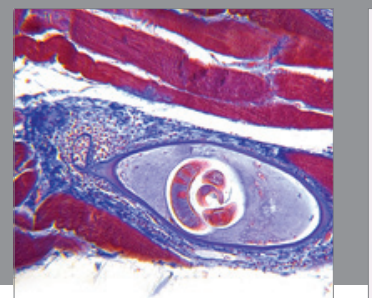

Gastroenterology

Research and Practice
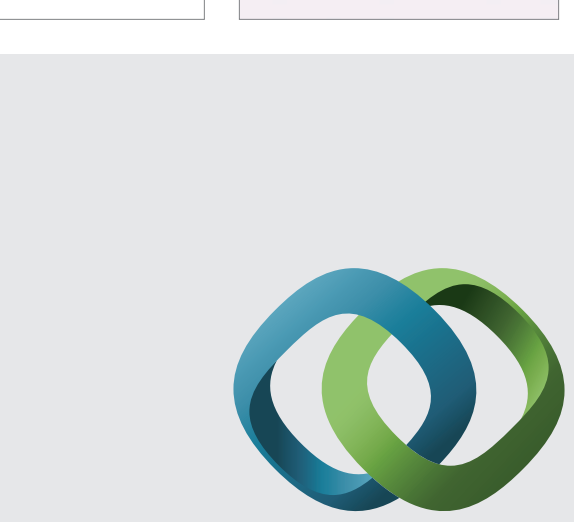

\section{Hindawi}

Submit your manuscripts at

http://www.hindawi.com
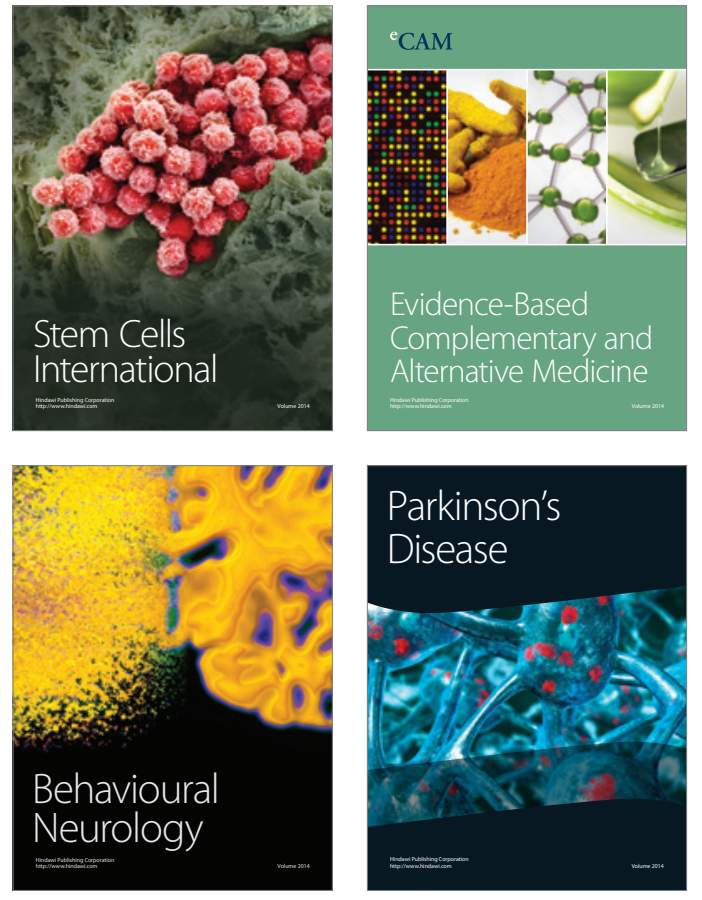
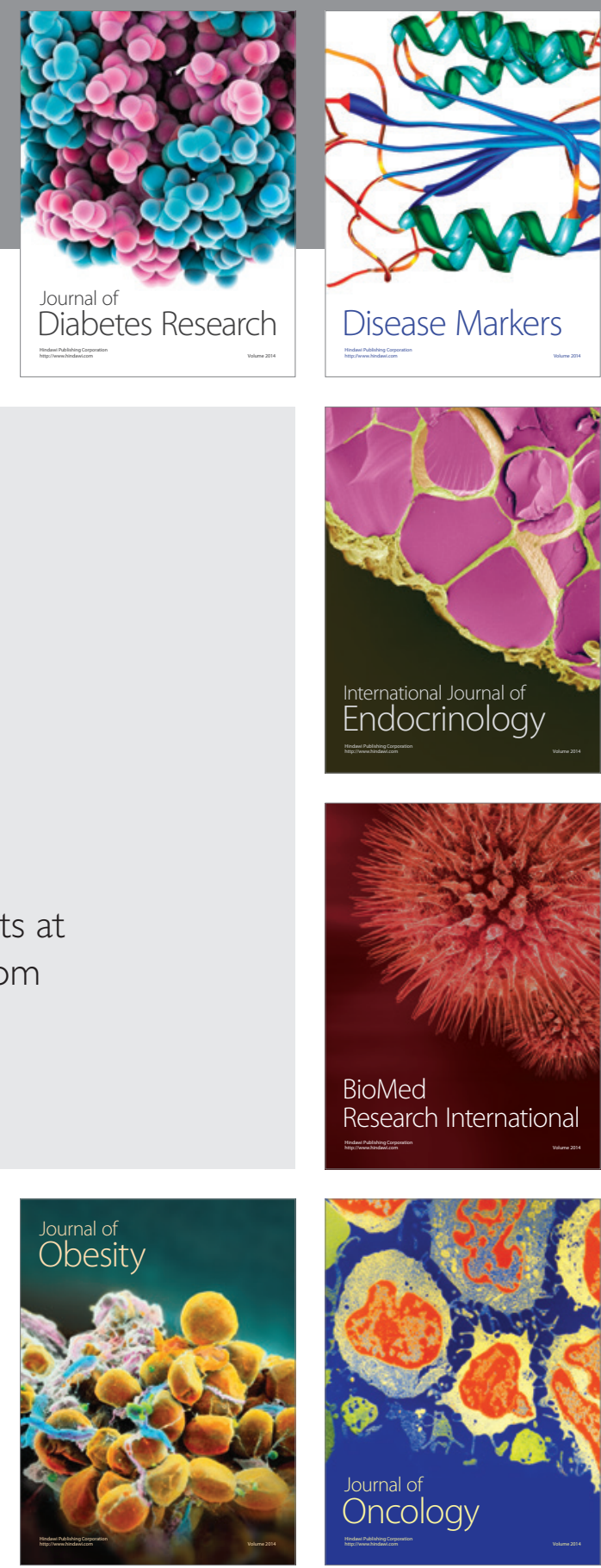

Disease Markers
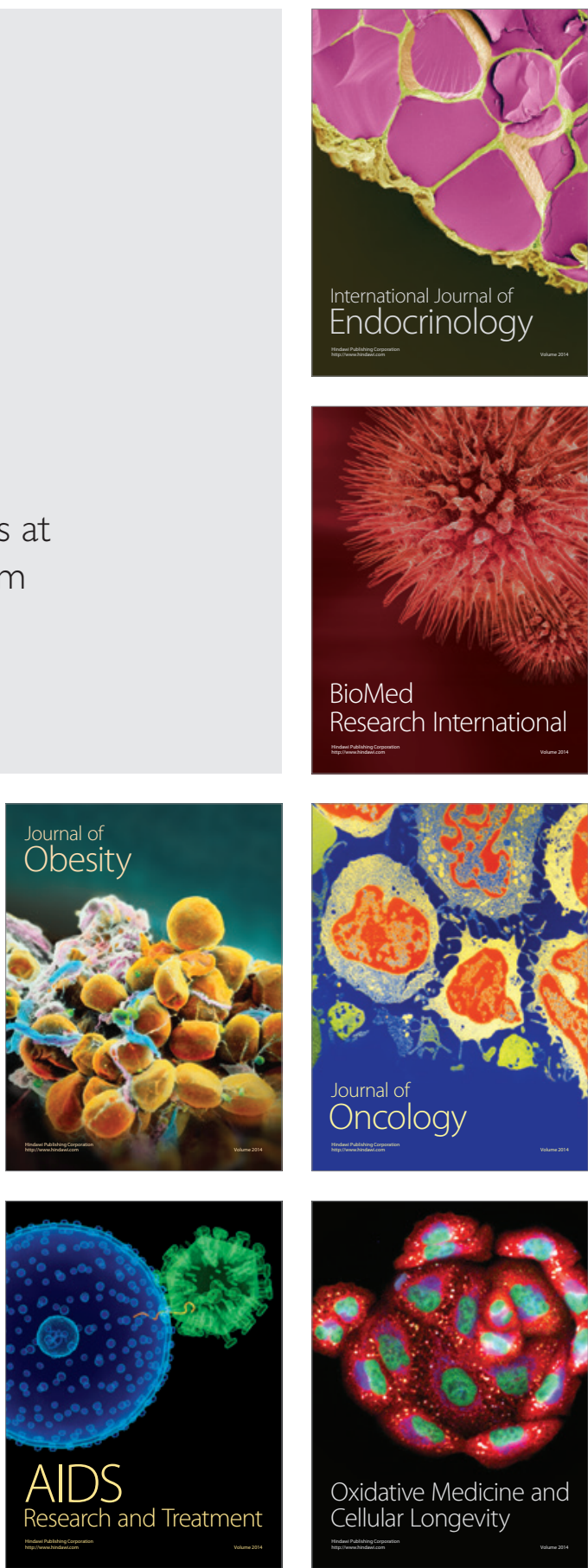